\title{
Live Action Role Play: Transmediality, Narrativity and Markers of Subjectivity
}

\section{Michał Mochocki}

Kazimierz Wielki University, Poland

michał.mochocki@gmail.com

ABSTRACT - This work frames larp as a multimodal medium: based on live-action role-playing but also open for inclusions of other media and technologies. It is approached as a narrative medium, used for performative and participatory cocreation of dynamic storyworlds. The emergent story is experienced by the full sensorium of the players' bodies and simultaneously uses the bodies as a medium of representation. Players combine the roles of authors, actors, characters, and audience. In its prototypical model, larp strives for a high degree of perceptual unity between player and character and prefers iconic representation via live action and live acting, with lesser importance of indexical and symbolic signification. This study reaches for J.-N. Thon's $(2014,2016)$ typology of forms of representation of character's subjective perception in film, graphic novels, and video games, and applies it to live-action role-playing. The fundamental difference lies in the 'firstperson audience' (Sandberg 2004; Stenros and Montola 2010) mode of participation in larp. Unlike the audiovisual media discussed by Thon, in which it is intersubjective perception that comes unmarked, larp by default is experienced from a subjective spatial point of view. The first-person audience mode makes it hardly possible to switch to (quasi-)perceptual overlay, and to ever leave subjective spatial point of view, unless some of the prototypical principles of larp are broken. By contrast, representations of (quasi-)perceptual point of view and of imagined internal worlds are possible, although with some danger of unwanted metaleptic contact with another character's delusions. For this and other reasons, larp has limitations in the use of simultaneous content markers and representational markers of subjectivity, whereas contextual content markers and all narratorial markers present no difficulty. The paper adds one category to Thon's framework: symbolic markers, which are based on a pre-established code of arbitrary signs and are used to regulate the active agency or perception of the audience, e.g. a player's gesture marking off-game status of the character, or movement from the main game area into a metaroom used for role-playing internal worlds. The overall discussion compares medium-specific affordances of live-action role-playing, which are fairly limited in 
representing subjectivity, to the affordances of larp as a multimodal genre, able to include many other forms of live, recorded and digitally mediated representation.

\section{INTRODUCTION}

Live-action role-play is a 'neglected child' of transmedia narratology, left unresearched by leading scholars in the field. When Linda Hutcheon, Mark J. P. Wolf, Derek Johnson, Henry Jenkins, Marie-Laure Ryan, or Jan-Nöel Thon "want to compare digital immersion to bodily immersion in a physical environment (where larp should definitely be referenced!), they reach for theatre or Disney theme parks and rides" (Mochocki 2016, 204). The situation is likely to change after the publication of Role-Playing Game Studies: Transmedia Foundations (ed. by José Zagal and Sebastian Deterding, forthcoming). In the meantime, I hope this paper also plays a part in drawing the attention of transmedia scholars to larp, which I attempt to achieve by connecting existing transmedia research to (live) role-playing studies. Comparative media analysis seems to be the most promising approach, as it enables putting larp on equal grounds with much-better-researched media.

The primary credit for intellectual inspiration should be given to JanNoël Thon for his "Subjectivity Across Media: On Transmedial Strategies of Subjective Representation in Contemporary Feature Films, Graphic Novels, and Computer Games" (2014, then expanded in Thon 2016). In order to avoid the terminological confusion that troubles the terms of 'perspective', 'point of view', and 'focalisation' (2016, 238), Thon introduced new four types of pictorial representations of character's subjective perception of the storyworld:

1. "Spatial point-of-view sequence" $(2014,73)$, i.e. character's sensory perception of the storyworld from his/her spatial location;

2. "(Quasi)perceptual point-of-view-sequence" (2014, 73-75), which includes spatial POV but modifies it with subjective perceptual filters (e.g. distortions of vision or supernatural perception);

3. “(Quasi)perceptual overlay" $(2014,75)$, which represents a character's modified perception of the world (e.g. hallucinations) not through POV but in third-person view (as in the Fight Club film; see section 5.2);

4. "Representation of internal worlds" (2014, 76-78), i.e. storyworlds imagined inside a character's mind, not linked to sensory perception of the physical surroundings (e.g. dreams, visions). 
Thon uses these four categories together with three types of markers of subjectivity (narratorial, representational, and content-based) in a comparative analysis of transmedial and medium-specific representations of character's subjectivity in film, graphic novels and video games. I would like to attempt to replicate Thon's study on the fourth medium: live-action roleplaying games.

This paper lays the necessary groundwork for such undertaking: first a discussion of larp as a trans-/multimodal storytelling medium, then a general analysis of larp-specific ways of representing its storyworld (also expanded in a forthcoming paper "From Live Action to Live Perception"). Beside Thon, whose concepts form the backbone of the following thoughts, the narratological approach reaches for Marie-Laure Ryan and David Herman. Their concept of the storyworld includes both a "semiotic blueprint" (i.e. verbal and non-verbal forms of representation in a medium) and "mental models" created in the minds of the audience (Herman 2009, 106-107; see also Thon 2016, 46-54). Given that, the discussion will include both the semiotic and cognitive aspects, following the example of Interactive Media: The Semiotics of Embodied Interaction that champions the combination of "the cognitive approach, the embodied phenomenological approach, and the semiotic approach" (O’Neill 2008, 43-44).

The last section contains a concise outline of representations of subjectivity in larp, built on Thon's conceptual framework comprising four types of representation, three types of markers (which I supplement with a fourth one), and their three temporal positions.

\section{WHAT IS LARP, WHAT IS LARPING}

J. Tuomas Harviainen $(2011,174)$, makes an important distinction: "larp as the singular event or series, which in turn contains the activity of larping" (original emphasis). He defines the activity as follows:

Live-action role-playing (larping, i.e. the activity performed within larps) is a type of pretence play, in which participants play fictional characters, and perform those character's actions physically, i.e. their body language and other non-verbal cues consistently correspond to those of the characters during play (or at least attempt to do so). Such play takes place in either a temporary 
space imposed upon a real place, or in public spaces temporarily redefined as play-space. (Harviainen 2012, 11)

This activity is based on three necessary conditions:

1. It has to be role-playing in which a character, not just a social role, is played.

2. The activity has to take place in a fictional reality shared with others, and breaking that fictional reality is seen as a breach in the play itself.

3. The physical presence of at least some of the players as their characters is necessary, or the activity becomes some other type of role-playing. (Harviainen 2012,3)

Rafael Bienia describes a whole larp event as follows:

larp is about physically playing an individual character, either of one's own making or made by the organizers for the event. Instead of following a script, a larp provides a situation for players as a starting point. This situation is embedded in a shared story world and involves problems that players can solve in character. The story unfolds when players decide on the basis of their character whether to solve those problems or not. (Bienia 2016, 60)

Bienia makes it clear that this description is rooted in the German larp scene. There are many differences in larp cultures between regions and nations (see Harviainen 2012,17), as well as between types (genres) of larp practiced within certain communities. This variety makes it virtually impossible to build a working definition that would universally apply to all subtypes. Instead, the understanding of larp may be based on a prototypical model demonstrating essential qualities, with individual larps deviating from it to various degrees.

For the purpose of this text, I will assume the following characteristics as prototypical:

1. Game master's authority: A larp is organised by the "game master(s), the person(s) responsible for creating, preparing and running the game", the functions named "Design, Preparation and Control" (Harviainen 2007), also known as larpmasters or organisers. These responsibilities may be shared with players to a very high degree (see Nordic collaborative design in Ashby 2017), but the lead organisers remain in charge.

2. Player-character unity: One player impersonates one character, ex- 
periencing the whole game from the character's point of view. A new character may only be adopted when the original character drops out of the game world (dead, or permanently incapacitated, or banished etc.). This 'personal' unity extends to player-character perceptual unity: at least part of the player's sensorial input is supposed to be identical with character's similar to method acting in the theatre (Bowman 2015).

3. Presence of NPCs: Some characters are NPCs (non-player characters), played by game masters or game staff, not by the regular playerparticipants. A person may impersonate different NPCs at different times during the game (no player-character unity in this case), or may be cast as one permanent NPCs for the whole game.

4. No external audience: There is no audience beyond the players, game organisers and staff. If there happen to be some off-game spectators, they do not constitute an audience, as the larp is not played towards them.

5. Iconic representation: Storyworld elements are represented mainly through iconic signs, i.e. character's body and actions are represented by player's body and actions, and physical elements of the storyworld by physical props and features of the game area. Symbolic and indexical signs are of secondary importance.

6. Pre-defined characters: Characters (PCs and NPCs) are created before the game (by game masters or by players themselves) as fictional personas with personal and social details, worldviews, pre-defined goals to pursue, starting resources (skills, tools etc.), and pre-defined relationships with other characters (including group membership).

7. Pre-defined storyworld: The fictional setting (storyworld) is designed (or selected) by the GMs and described to players before the game, usually in writing and with illustrations. It is expected that players will take effort to maintain the illusion of continuity and coherence of the storyworld.

8. Pre-defined game mechanics: There is a set of special protocols used to represent (inter)actions that the participants may not want (violence, sexuality) or be able to (supernatural powers, futuristic technology) perform as real physical action. Some game mechanics are rule-based "resolution systems for conflicts" (Harviainen 2012, 68). Other mechanics "also cover issues such as pre-determined play time, rules on breaking game continuity and acceptable clothing and props" (Harviainen 2007). A special subset of game mechanics are metatechniques (see 5.4).

All in all, larp fulfills the requirements Ryan set for the most advanced 
form of interactive drama:

abolish the difference between author, spectator, actor and character. As beneficiary of the production, the interactor is audience; as active participant in the plot and member in make-believe of the fictional world, he is character; as physical body whose actions and speech bring the character to life, he is actor; and as initiator and creative source of the character's speech and action, he is co-author of the plot. (Ryan 2001,318-319) ${ }^{1}$

What Ryan mentioned as an ideal form - never fully achieved either in experimental theatre or in virtual reality - happens to be the basic interaction "engine" in larp.

\section{LARP AS A NARRATIVE MEDIUM}

In Storyworlds Across Media (2014) Ryan talks about "three dimensions of mediality" $(2014,30)$. The "Cultural dimension addresses the public recognition of media as forms of communication and the institutions, behaviors, and practices that support them" (ibid.). In this regard, the medium of larp as a cultural practice or art form is recognised next to the theatre, video games, or comic books, and next to other practices that include the activity of live-action (i.e. physically performed) role-playing (see Harviainen 2011, 2012, above).

The technical dimension includes "any kind of mode of production and material support" (Ryan 2014, 29). In larp, the primary mode is liveaction role-playing in which, just like "in the theater or in ballet, the human body fulfills both of these functions ... the mode of production cannot be distinguished from the material support" (ibid.). But larp does not rely on live-action role-playing only: it is a multimodal (mixed media) form open for oral storytelling, writing, music, numerical game mechanics, stage decoration, as well as photography, film, and advanced digital technologies (computers, mobile phones, augmented reality, wearable tech etc.). This multimodality radically broadens the narrative and experiential affordances of the genre (see Ryan and Thon 2014, 10): in the technical dimension larp can reach far beyond mere live-action role-playing.

${ }^{1}$ Interestingly, this passage can only be found in the first (2001) edition of the book.

International Journal of Transmedia Literacy - 4 - December 2018

http: //www.ledonline.it/transmedialiteracy - Online ISSN 2465-2261 - Print ISSN 2465-227X 
The dimension of "semiotic substance encompasses categories such as ... language, image, sound, movement, face-to-face interaction" (2014, 29-30), all of which are included in the primary mode of live-action roleplaying. The human body interacting with the physical environment of the game space (including costume, props, set decoration, and all objects and materials available in the game location) can communicate meanings through all these semiotic channels (multimodality of the medium; Ryan and Thon 2014, 10). Additionally, there is language- and image-based material, as well as the above-mentioned physical materials, created before the game (for a detailed discussion of physical materials in larp, see Bienia 2016, 59-90). Just like advanced VR, larp is multisensory and may include "all forms of representation, action and signification", i.e. is "omnisemiotic” (Ryan 2015, 46).

It may be argued that live-action role-playing is, for the most part, an unmediated experience, with verbal and physical actions being performed directly (speaking, writing notes, opening doors, walking, picking up items etc). I would agree with Hakim Bey's idea that mediation is a scalable quality, with live performance arts being "less mediated than others" $(1994,7)$, and I do concede that larping has a relatively low level of mediation - but it is still one of the media. I will argue for the mediality of larp on three grounds: a) human action as a medium, b) mediation through character's consciousness, c) medium for narratives.

First of all, as Harviainen explains with a reference to Paul Ricoeur, interpersonal contact entails "the process of seeing meaningful actions as text" (Harviainen 2012, 98), so in this view a player's action is a medium that communicates meaning. This is reminiscent of Chatman's idea of mimetic narrative, or "telling" through showing (Chatman 1990, 111-118). Basically, "the physical act of opening a mouthpiece and uttering a few words gives us the medium of speech, where sounds are formed and carried through the physical medium of air. Similarly, the flick of a wrist and the wink of an eye give us gestures by which we can also express ourselves, where our bodily movements in space and time are our medium of expression" (O'Neill 2008, 10). For the acting player, this can be seen as "meaning-making through playful action (ludosis)" (Mäyrä 2008, 19). For coplayers witnessing the action this would be "decoding of messages or media representations (semiosis)" (ibid.). In the process analogical to "stage semiotisation" in theatre (Elam 2005, 5-7), the perceived actions of co-players are interpreted as actions of the imaginary character. 
As the second aspect of the mediality of larping, it is "by nature an embodied performance of sign-systems through a fictional role but by the physical player" (Harviainen 2012, 52), termed by Marjukka Lampo (2011) as "transportative performatic behaviour": transportative to character's consciousness. Even though a player's in-character physical action (speaking, walking etc.) is immediate and feels unmediated, it is not interpreted by co-players simply as an action of the real player-person. Analogically, their own experience of the larp is not simply interpreted as experienced by their real selves. It is all framed within the shared discourse which maintains a fictional storyworld used for "intentional evocation of artificial experiences through the use of fictional characters" (Harviainen 2012, 3-4). This interpretative framework relies on "a protagonist's consciousness for its centre of cognition, intellection and subjectivity" (Fludernik 2005, 36). The character's subjective point of view is a "filter" (as in Chatman 1990, 143) through which most in-game experiences are mediated.

Finally, I will invoke the argument made by Marie Laure-Ryan's about oral storytelling: "from the point of view of narrative it certainly fulfills the conditions of mediality because the live performance of face-to-face interaction makes a difference as to what kind of stories are told, how they are told, and why they are told" $(2014,28)$. Live-action role-playing is a narrative medium because it is a unique way of creating/experiencing narratives as "quasi-mimetic evocation of 'real-life experience" (as in Fludernik's idea of experientiality in narratives, 2005, 9), its nature reflecting both the performative turn in culture, and the participatory turn within performance (Pearce 2016, 446; Fedoseev 2014, 104-105).

\section{REPRESENTATION IN LARP: WHAT TO WHOM BY WHOM}

The "text" / meaning / informational content that is represented in a larp is its fictional spatio-temporal continuum (diegesis) with its actors and their actions, as they are experienced by player characters. The "total larp experience" (Bruun 2011, 196) includes more than the play itself: it starts with an extended pre-larp phase, in which a significant part of world-building takes place. In line with transmedia narratology, I will use the term storyworld to encompass the setting, the characters, and the plot. Ryan (2014) divides a storyworld's contents into: existents (characters and objects), 
setting (space), physical laws ("principles that determine what kind of events can and cannot happen in a given story"), social rules and values ("principles that determine the obligations of characters"), events ("the causes of the changes of state that happen in the time span framed by the narrative"), and mental events ("the character's reactions to perceived or actual states of affairs") (34-37). Narrative agency is distributed among the GMs (organisers), NPCs and players: GMs create the setting, its physical laws, and social rules and values; GMs and players together create characters and objects (e.g. costumes and props) that match the pre-defined setting, laws and rules; and everybody can generate live events during the game (and invent fictional past events). Mental events belong to the characters, so they are individually created by the players, but as will be discussed further, there are ways for GMs to influence it by invading a character's perception.

Players are introduced to the storyworld before the game, as the GMs provide them with "setting material, character material, genre information and game mechanics" (Harvainen 2007). Fatland uses 'pre-diegesis' as the term "for that single consistent diegesis that larpwrights author before a larp begins" $(2005,153)$. In this case, the communication has clear authors/senders (game masters), audience/recipients (players and staff), and text/message in recorded form (written documents, usually with addition of images, sometimes with audio-video materials). Players also know in advance the individual characters they will role-play: sometimes authored by the GMs, sometimes by the players themselves ${ }^{2}$ (in which case the GMs are the audience). When the players have arrived on site, the GMs recapitulate essential storyworld information (and/or add new information) in an oral briefing. Optionally, the GMs may run workshops, which in addition to "disseminating the organizers' visions of how participants should play the game" can also "range from getting to know the game world to building game characters and character relations" (Bruun 2011, 196). The narrativity (or narr-ACT-ivity, to use Booth's term (2009)) of larp is therefore parallel to drama, virtual reality and everyday life:

2 Big 'blockbuster' larps of the late 2010s are known for extended pre-game periods in which players collaborate to develop detailed backstories and relationships. It is worth noting on the margin, but not (not yet?) prototypical. See Ashby 2017 for an in-depth discussion of pre-game in College of Wizardry. 
Drama, life, and VR create narrative material with characters, setting, and actions but without narrators. In contrast to narrated narratives, simulation systems do not re-present lives retrospectively, fashioning a plot in which all events are in the book and all the potential narrative material is available to the storyteller, but instead generate events from a prospective point of view, without knowledge of their outcome. (Ryan 2015, 49)

When the game begins, the primary mode of communication (and cocreation) is live-action role-playing performed by players and NPCs (GMs may adopt the role of NPCs). At this moment the status of authors, audiences, texts and storyworlds becomes complicated, as "corporeal participation ... can be termed world-creative in the same sense that performing actions in the real world can be said to create reality" (Ryan 2015, 208). All live-action players are first-person audience (Sandberg 2004, 274; Stenros and Montola 2010, 20; Montola 2010, 4; Montola 2012, 89-94): co-authors and audiences at the same time, communicating narrative information through their words, acting and actions, be it intradiegetic (in-game / incharacter) or extradiegetic (off-game / out of character, e.g. with game mechanics). Each player speaks and acts on behalf of his/her character in the collective story. "Those bits are then 'read' as 'text" (Harviainen 2012, 88 ), and because larps are "consistent information environments ... they can turn actions into a narrative unity" $(2012,88)$. Players can also contribute to the storyworld passively, as targets of someone else's action, or by mere presence as a character (witness) in this particular location, which also contributes to "a physical simulation of an imaginary world" (Pearce 2016, 448).

Beside the performance of their own actions, players experience the ongoing events by watching the live actions of others (live action is "read" in live perception). Players can also invent their character's thoughts and emotions (Ryan's mental events) just in their minds, not communicating it to anyone yet adding these elements to the personally experienced story, such as a secret love for another character (Hitchens and Anders 2009, 55). This is similar to Herman's comment on storyworlds in "a tale that is projected but never actualized as a concrete artifact - for example, stories about ourselves that we contemplate telling to friends but then do not, or film scripts that a screenwriter has plans to create in the future" (2009, 106). Larping seems to be the embodiment of Talmy's claims: "the perceiver of a narrative need not be an entity separate from its producer ... a 
producer can create a narrative without any separate sentient entity to perceive it ... that producer will function as a perceiver as well, even if only in the course of production" (Talmy $2000 \mathrm{I}, 418$ ). On the other hand, players can communicate their mental events to co-players if they want to do so and in doing so they will reveal their character's subjectivity.

Beside the "bits" of meaningful actions communicated live by each player and NPC to co-players and game masters, there is narrative agency executed by the GMs through other modes than live-action role-playing. Larp "has the advantage of containing embodied reactions as well as digital or abstract representations" (Harviainen 2012, 11). The GMs may supplement larping with extradiegetic oral narration, extra- or intradiegetic text messages (digital or on paper), technological special effects, physical manipulation of objects and decorations etc. These non-larping modes may be used to communicate with all players, just like a stage drama uses special effects for theatre audience, e.g. voice recording (McIntyre 2003, 89-90), "elaborate mock-ups, back projection and film" (Elam 2005, 15) (see also Artaud's manifesto for total theatre in Ryan 2015, 224). What differentiates larp from audience-oriented theatre is the possibility to use other media and technologies to target individuals to create unique perceptual effects for that single player (see below).

Summing up, larp as a medium is based on "many-to-many" (Shirky 2008) communication:

1. NPCs and players are constantly producing meaningful actions "read" by all who are perceiving them,

2. GMs' messages about the storyworld are being constantly communicated to players by the physical materials and resources available in the game area (including physical props and set design), which are "read" both as semiotic representations and as affordances for interaction,

3. GMs may dynamically add new elements (and change the existing ones) as the larp is progressing, using any tools and media channels they have at their disposal.

In what follows, larp is taken to "consists of multiple texts that interact with each other" (Harviainen 2012, 5). On the one hand, the sum of all individual texts can be treated as one collective narrative: "one takes the total events of a larp and condenses them into a singular story" (Harviainen 2012, 48), as "a world's history is the sum of the personal histories of all of its members" (Ryan 2015, 164). Nonetheless, in practice, no single person could have access to all words and actions of all participants: a major differ- 
ence to stage drama in which the audience is a "sanctioned overhearer" (McIntyre 2003, 6) of all conversations of all characters ${ }^{3}$. In larp, just like in real life, one cannot witness events happening simultaneously in different locations (e.g. adjacent rooms), or follow several simultaneous conversations. Larp follows the model of "braided plot" or "classical narrative ... a sequence of physical events objectively experienced by a group of characters, but every character in the cast lives these events from a different perspective and has a different story to tell" (Ryan 2015, 173). A player's perspective is thus limited to what s/he has witnessed and been informed about, with allowances for mistakes, forgetfulness, and deliberate deception, and "mainly provided by the cognitive ability of directing one's attention" (Ungerer and Schmid 2006, 210, original emphasis).

It may be metaphorically said that each of us lives in a different world, meaning that each mind operates on uniquely subjective cognitive models of the world. I would argue for an analogical approach to the fictional storyworld and its many subjective visions in larp:

1. A larp event has one storyworld ("text", or diegesis) collectively created by contributions (multiple small "texts") from GMs, NPCs and players. In Ryan's (1991, vii) typology of possible worlds, this is the TAW: textual actual world.

2. Participants perceive ("read") only fragments of the whole TAW, limited by their physical access, sensory perception, and attention. As a result, the personally experienced storyworlds (subjective diegeses in Montola and Loponen) will be only partially overlapping but complementary.

3. Each personal experience of the storyworld (fragmentary "reading") is filtered through the individual character's point of view and constructed in player's cognition. As a result, the subjective diegeses (interpretations of the "text") of two players may be mutually incompatible even if the players were exposed to the same fragments. In Ryan's (1991) terms, the subjective visions of the storyworld in characters' minds, if incompatible with the TAW (textual actual world), are APWs: alternative possible worlds.

3 In fact, this may be said to be true about «prototypical» versions of theatre performances - experimental theatre is known to have violated this principle (see Ryan 2015,224 for examples).

International Journal of Transmedia Literacy - 4 - December 2018

http: //www.ledonline.it/transmedialiteracy - Online ISSN 2465-2261 - Print ISSN 2465-227X 
After a completed larp, each player will have remembered the story as a single linear narrative consisting of events experienced and witnessed by his/her character (Harviainen 2012, 49). Just like the cognitive practice in real life, "a perceiver regularly construes the sequence of personal experiences he has had over time - both interior and externally based experiences - as constituting a narrative, that of his "life" (Talmy 2000 I, 418). This personal story will be contextualised in the "pre-diegetic" storyworld information delivered by the GMs before the game (textual reference world, as in Ryan 1991). It will also be extended by second-hand knowledge about other characters' actions and events which the player did not witness but heard from other characters of the GMs.

Up to this point, I have explained my approach to the questions of mediality, narrativity and diegetic status: larp is a performative, participatory, narrative, and multimodal medium. It consists in collaborative and emergent authorship of a story set in a single fictional storyworld, which is individually experienced as a personal narrative from the subjective perspective of one character. Delving into the complexity of all information circulation in larp is beyond the scope of this paper, and it was already done in Harviainen's dissertation (2012). Here, the pre-larp and post-larp storyworld information was touched upon as relevant context for the main focus: player character's perception of the storyworld as the game is running live. In other words, my exploration of subjective representations in live-action role-playing is focused not so much on live action as on live perception (see also Mochocki, forthcoming). This will include live perception of physical objects and features of the environment, and of live actions of players (including one's own).

\section{REPRESENTATIONS OF SUBJECTIVITY IN A LARP}

One issue separating larp from audio-visual media is the character-player perceptual unity which causes certain limitations to the use of simultaneous markers of subjectivity. In order to clarify the issue of markers of subjectivity in the specific context of larp, I will first take a look at how subjectivity and subjective representation are understood by J.-N. Thon (2016). The subjective mode should be first distinguished from the objective and intersubjective ones.

Objective representation "suggests that the storyworld elements in 
question are not perceived or imagined by any characters at all" (Thon 2016, 240). In larp, the objective structure of the storyworld is primarily created as pre-game information ('pre-diegesis' in Fatland 2005, 153) on the game's website, in printed hand-outs, and in spoken narratorial introduction by the organisers. In larps set in popular media franchises, the whole transmedia universe becomes the default setting (Mochocki 2016; Torner 2017). Increasingly popular are large-scale design documents, e.g. for College of Wizardry (since 2014).

Intersubjective representation presents "storyworld elements as they are (intersubjectively) perceived or experienced by a group of characters" (Thon 2016, 240). Interestingly, some scholars reject the very existence of a single coherent storyworld in an ongoing larp. Montola (2003) claims that each player constructs a subjective personal diegesis, and the essence of larp consists in sharing and synchronising these subjectivities. Nevertheless, in this paper I take a different approach: "two forms of diegesis exist, the subjective and the objective. The subjective is created by the player's subjective interpretations", whereas the intersubjective (Andreasen says 'objective') one is the synchronised amalgam of all personal diegeses interacting through in-game communication (Andreasen 2003, 77). Terminology-wise, I will here understand Andreasen's 'objective diegesis' as Thon's intersubjectively perceived storyworld.

The subjectivity Thon focuses on is "the subjective representation of a character's consciousness or mind" (2016, 238, original emphasis), one that "suggests that the storyworld elements in question are perceived or imagined by only one character (and often in a way that is not compatible with an intersubjective version of the storyworld)" (2016, 240).

As Thon observes, "At least in contemporary films, comics, and video games, intersubjective representation may be considered the unmarked case, while objective representation_and subjective representation may both be considered marked cases" (ibid.). Therefore, Thon repeatedly draws attention to markers of subjectivity: cues provided by the creators to audiences in order to signal a transition from the intersubjective to subjective mode. He distinguishes:

1. Narratorial markers, e.g. character's internal voice spoken on audio $(2016,279)$ or written as text $(2016,293)$.

2. Representational markers (nonnarratorial), "such as filters, blurred lines, or unusual coloring in order to communicate the subjective quality of what is being shown" $(2016,259)$. 
3. Content markers (nonnarratorial), "where what is represented rather than how it is represented communicates the different ontological status of the following or the preceding segment(s) of the representation

(2016, 263), e.g. character falling asleep, or taking a hallucinatory drug. In terms of temporal relations to the marked sequence, markers may be simultaneous (appear during the subjective sequence) or contextual (before or after, called by Thon 'a priori' and 'a posteriori'). Representational markers on the audio-visual media are usually simultaneous, but may also be contextual ("such as zooms on characters' faces or white fades that are sometimes used to mark the ontological transition” (2016, 263). Content markers are usually contextual, either a priori announcing a subjective sequence (character falls asleep), or a posteriori framing the previous sequence as subjective (character wakes up) $(2016,265)$. Simultaneous content markers are also possible, when "the represented events quite clearly fail to follow the rules of the previously established diegetic primary storyworld" $(2016,293)$ and "cannot readily be plausibilized as part of the diegetic primary storyworld's 'factual domain'” $(2016,284)$.

In fact, all three categories (narratorial, representational, and content) may appear in each of the three temporal relations (contextual a priori, simultaneous, or contextual a posteriori), as markers of any of the four ways of representing subjectivity.

\subsection{Spatial POV in Larp: The Unmarked Mode}

The default mode of representation is a major difference between larp and film, graphic novel and video games discussed by Thon. In the audio-visual media, intersubjective perception is unmarked, whereas all subjective representation needs to be marked. In larp, by contrast, it is the subjective spatial point of view that comes unmarked. Each character perceives the storyworld through the senses of the human player from his/her spatial position (Montola 2004, 159; Fatland 2005, 153-154), sometimes modified by the costume and equipment (see Bienia 2016 on the role of material objects in player's experience). No markers are needed to communicate this - they are needed to signal deviations from this mode.

Although spatial POV (point of view) in film theory refers to "segments of a narrative representation where the storyworld is pictorially represented from the spatial position of a particular character" (Thon 2016, 
259), it should not be limited to visuality. Thon draws attention to perception of sound (citing Michel Chion's term of 'point of audition', 260), and to game-specific perception of areas affording action (here Thon reaches for Britta Neitzel's 'point of action', 235). In larp, I would name it 'point of live experience', or 'point of live interaction', combining a physically embodied (thus spatially located) sensory perception of the surrounding environment with the affordances for physical, verbal, mental, and social (inter)actions within it. The embodied presence includes full sensorium - not only "primary internal ocularization" and "auricularization" (Jost 2004, 75) known in film studies but also sensorialisations related to the cutaneous (tactile), gustatory, olfactory, kinaesthetic, vestibular, and (partially) organic perceptions (Taiwo 2009, 110).

\subsection{Quasi-perceptual Overlay: The Absent Mode}

The principles of no-audience, player-character unity, and first-person POV are incompatible with third-person overlay. When the player is roleplaying the scene live, s/he cannot adopt the third-person view. Quasiperceptual overlay in a larp is only possible when a player can watch his/her character role-played by another player. It could be achieved in experimental jeepforms (to be discussed in a forthcoming paper) - not in a prototypical larp.

\subsection{Quasi-perceptual POV: A Marked Mode}

Quasi-perceptions in larp need to be marked. Markers may be used by players, NPCs or gamemasters (or GM-instructed staff).

Narratorial markers seem to work analogically to film, video games, and graphic novels, in whatever temporal relation they appear (a priori, simultaneous, a posteriori). However, the affordances to use these markers are unequally distributed among players and gamemasters. For example, the GMs may use extradiegetic narratorial voice (or writing) to represent characters' quasi-perceptions to selected players, or they may instruct nonplayer characters to use the affordances available to regular players. A player may use his/her character as an intradiegetic speaking (or writing) narrator to mark or describe quasi-perceptions to other characters, or s/he may 
use metatechniques for intradiegetic thinking narration to co-players (not characters).

Content markers in the form of live action/acting (including speech acts) may be used by players and NPCs for intradiegetic communication of their character's quasi-perceptions (a prori, a posteriori, and simultaneous). Larp may replicate the use of a priori contextual content markers from other media, for example, the player pretends to be taking drugs before $\mathrm{s} / \mathrm{he}$ starts acting out narcotic delusions. Analogically, s/he may use an a posteriori contextual marker, pretending to be waking up with a headache and no further delusions. As simultaneous content markers, the player may use body language, acting, movement etc. to represent being blinded, held in place by invisible powers, chasing or being chased, or talking to someone nobody else can see. Additionally, the GMs may use physical props, NPCs and light, sound, smell etc. effects to represent quasi-perceptions to the perceiving player.

GM-controlled quasi-perceptions are problematic when represented as physical content in a space shared with other characters, as any contact between the quasi-perception and another character would be metaleptic (for example: a monster from one character's hallucination should not physically touch another character, as it does not exist in the other character's world). The use of simultaneous content markers by GMs is thus either limited to single-player spaces, or needs extra organisational effort and collaboration from co-players.

The use of representational markers in the absence of post-production editing is limited. Marking a character's quasi-perceptions on the level of representation must affect the player's embodied perception though the use of filters on the represented storyworld elements (light, colour, sound, smell, smoke, vibration etc.) The GMs may modify the single player's sensorial input: limiting the vision, hearing or movement, or technological enhancement (e.g. nightvision goggles), or affecting the organism of the player (e.g. alcohol or sleep deprivation). The GMs may also use another mode of representation instead of physically performed role-play, e.g. gamemastered tabletop role-playing, or non-interactive cutscene prepared by the GMs for the target player.

For instance, After Midnight Shadows Moan, a 2015 game by Joanna Płaszewska, exemplifies several technical means of modifying players' subjective perception only with costuming and lighting (see Figures 1-4). 


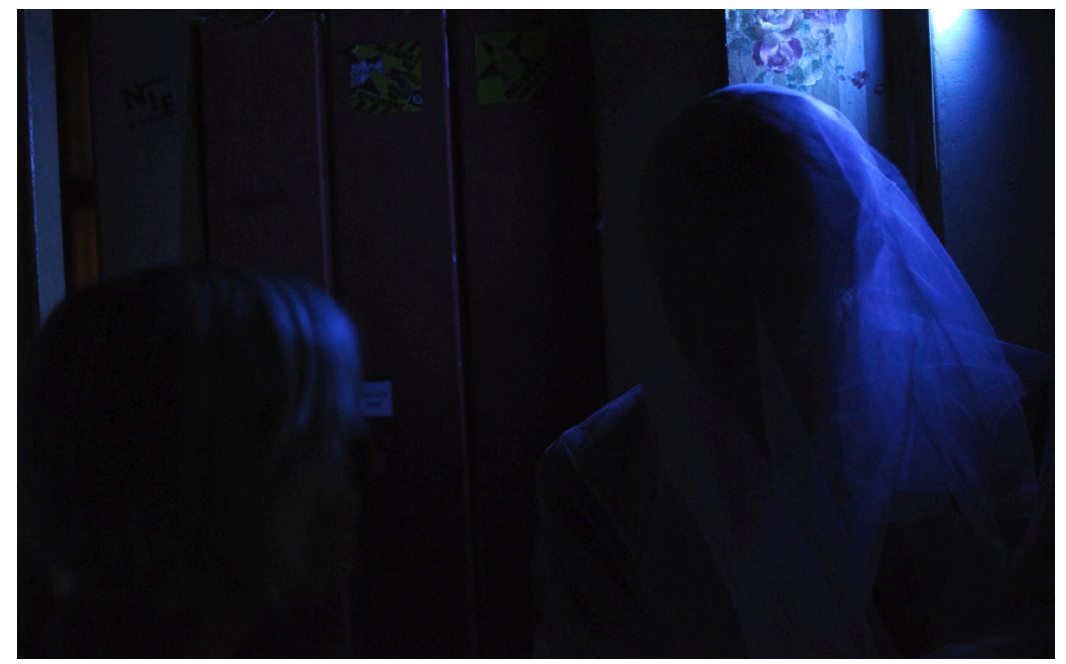

Figure 1. Ghost players wearing white veils, off-game. After Midnight Shadows Moan, photo by Joanna Ptaszewska.

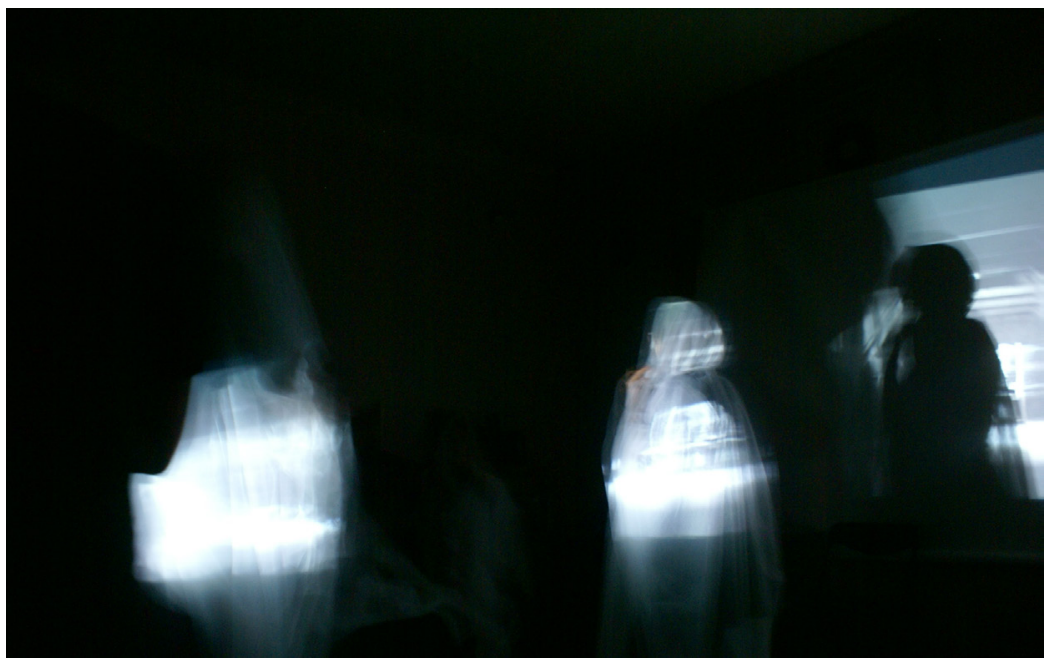

Figure 2. Ghost player interacting with human player, in-game. After Midnight Shadows Moan, photo by Joanna Ptaszewska.

International Journal of Transmedia Literacy - 4 - December 2018 http: //www.ledonline.it/transmedialiteracy - Online ISSN 2465-2261 - Print ISSN 2465-227X 


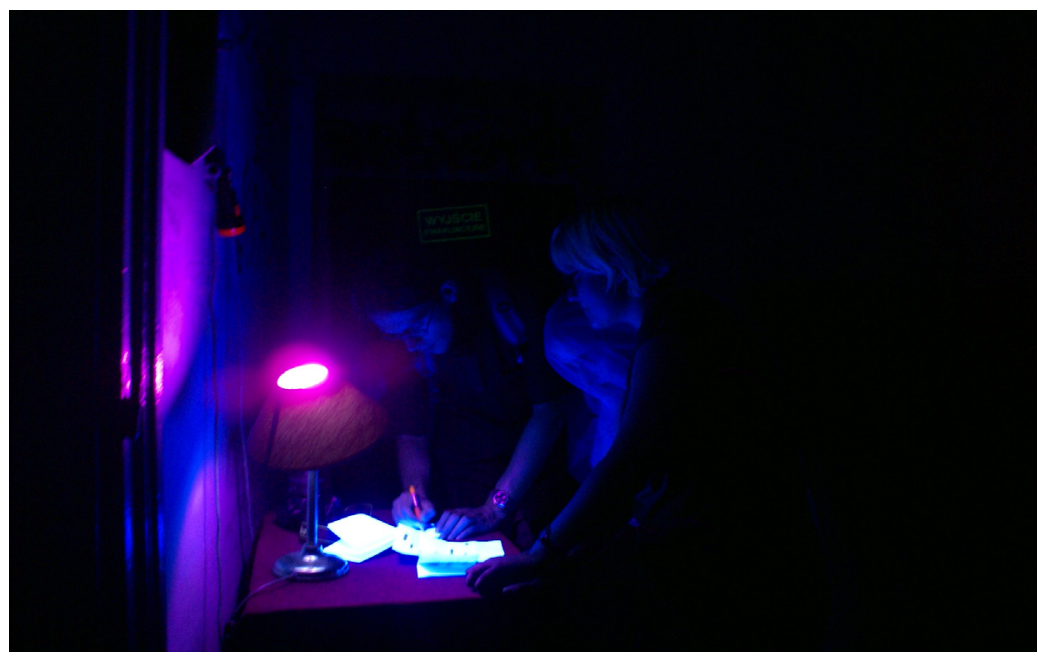

Figure 3. UV lamp and its effect on white sheets of paper. After Midnight Shadows Moan, photo by Joanna Ptaszewska.

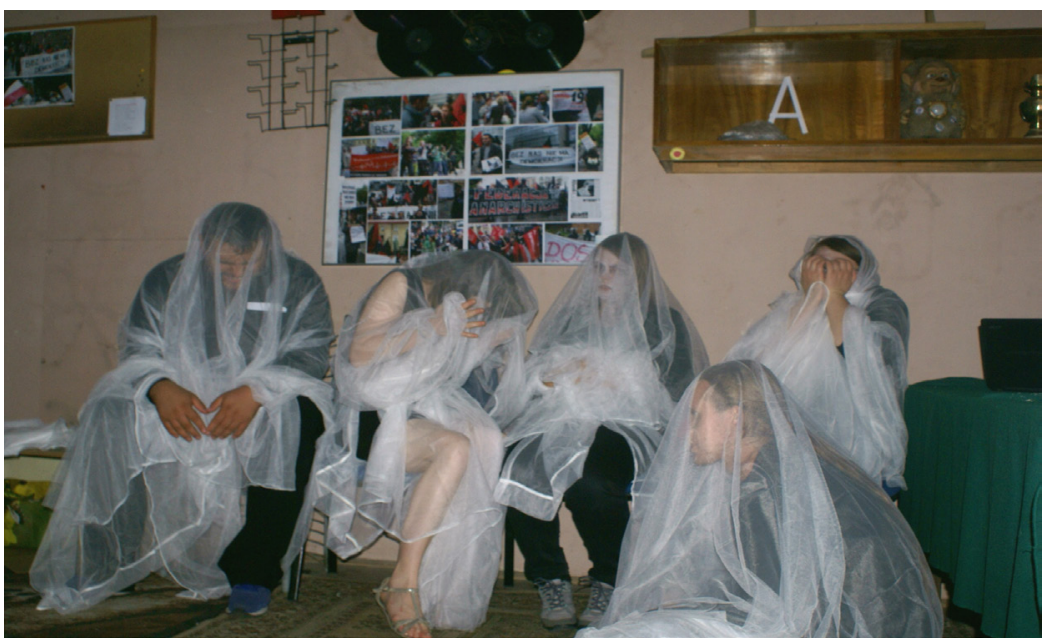

Figure 4. Overhead projector and its effect on the ghost veils. After Midnight Shadows Moan, photo by Joanna Ptaszewska.

International Journal of Transmedia Literacy - 4 - December 2018 http: //www.ledonline.it/transmedialiteracy - Online ISSN 2465-2261 - Print ISSN 2465-227X 


\subsection{Symbolic Markers in Personalised Subjective Perception}

Ultimately, I find it necessary to add a new type of marker to Thon's list of narrative, content and representational markers: symbolic. Symbolic markers require the player to imagine storyworld elements signified by arbitrary signs according to a game-specific code established between the GMs and players. Typically, symbols such as game mechanics are known to all players and intended for intersubjective communication. How can they be used for personalised subjective perception?

1. Symbols which are unique for a particular player may represent quasiperceptions for this character in a way unnoticed by co-players (simultaneous markers).

2. Other symbols may be pre-defined as beginnings and ends of subjective sequences (contextual markers).

3. Symbols pre-defined as simultaneous markers of somebody's quasiperceptions may be used to signal to co-players that their characters cannot perceive those elements - or that they perceive it differently (see larp Delirium, Heebøll-Christensen, Thurøe and Munthe-Kaas 2011, 85).

4. Symbolic markers may be combined with narratorial markers in metatechniques. Available metatechniques are usually pre-determined by the GMs and explained to players before the game to reduce the risk of miscommunication. Some are created specifically for player-directed narratorial intrusions, e.g. the monologue box (Edland, Lindahl and Raaum 2011, 103). Interacting with co-players, the player signals the monologue box by a hand gesture: draws a square in the air to start, and then to end an internal monologue (symbolic marker). Whatever the player says within the monologue box is counted as unspoken thoughts, which separates the communicating player's behaviour (speaking) from that of his/her character's (not speaking). This also breaks the player-character perceptual unity for co-players: they could hear it but their characters could not.

The monologue box can be compared to soliloquies on stage, narration boxes and thought bubbles in graphic novels, and voice-over in film (see Thon 2016, 389). Not all uses of such meta-communication will actually be narratorial or quasi-perceptual - but using an internal voice to reveal one's quasi-perceptions as an "intradiegetic thinking narrator" (Thon 2016, 184) is one of the options. 


\subsection{Internal Worlds: A Marked Mode}

Within the diegeses of internal worlds, all markers of subjectivity may be used to represent quasi-perceptions in the same way as in the primary storyworld. Again, there is a diegetic challenge with allowing co-players to participate in one character's internal world. Co-players could play different characters or dream versions of their main characters, but the main characters in the primary storyworld should stay unaware of what happened in the dream (unless the storyworld gives them access to someone's dream world). But as long as the dream sequence is played in an area inaccessible for other characters from the factual storyworld (i.e. in separate metarooms), there is no danger of metaleptic physical collisions.

Unless the dream world is the whole and only diegesis, the larp needs markers of transition between the factual primary storyworld and one character's internal world. Narratorial markers may be used by the GMs analogically to other media: to announce (extradiegetically) a dream sequence $a$ priori and a posteriori, and as simultaneous voice-over for the whole dream or vision. Players can do so in character's voice as intradiegetic speaking narration a priori and a posteriori. They may also narrate internal-world events as intradiegetic speaking narrators or intradiegetic thinking narrators.

Contextual content markers also work as they do in other media, with the most obvious example of the character falling asleep or waking up (this needs a character as the acting figure, so the GMs can use it only through an NPCs or in collaboration with an instructed player). Simultaneous content markers cannot signal the ontological transition on their own - unless supported by other markers, they would be read in a larp as markers of quasi-perception.

Symbolic markers may be used by the GMs as contextual markers of beginnings and ends of dream sequences for all players in the perception range. If there is a delineated space (metaroom) to role-play internal worlds, the physical act of crossing the boundary by a player is a symbol of transition between worlds. 


\section{CONCLUSION}

Larp has been discussed as a multimodal medium: based on the activity of live-action role-playing as its primary mode of representation, and open for theoretically unlimited additions of other media and technologies. It is also a narrative medium, used for performative and participatory co-creation of emergent stories, with players combining the roles of authors, actors, characters, and audience. The prototypical model of larp was framed as consisting mainly in its primary mode, preferring iconic representation of the storyworld through live action and live acting, with one player impersonating one character for the whole time, and striving for high degree of perceptual unity between the player and the character. The total larp experience includes pre-game preparation of characters, storyworld setting, and interaction rules (mechanics) by gamemasters and players; the live run of the larp with player characters, non-player characters and organisers; and post-game communication. A part of the pre-larp, off-game and post-larp communication may be objective or intersubjective representation of the storyworld, but the in-game perception by default is focalised through the subjective perspective point of the character, shaped by the subjective spatiotemporal position, sensorial perception, and embodied cognition of the player. In many cases, players sharing the same physical space will have virtually identical perception of the surroundings, so their conceptualisations of the characters' spatial POVs will be (intersubjectively) highly coherent - but never fully identical.

The application of J.-N. Thon's (2016) framework sheds some light on similarities and differences between the audiovisual media and larp. A major difference is found in their default mode of representation which does not need to be signalled with markers. In the audiovisual media, it is intersubjective perception that comes unmarked. In larp, it is subjective spatial point of view. Generally, markers of subjectivity may easily switch a larp character's perception from spatial POV to quasi-perceptual POV. Also, a whole larp or its part may be framed as a representation of internal worlds (still, experienced in the first person). The most difficult case is Thon's quasi-perceptual overlay, which can only be achieved in nonprototypical larps that use metatechniques, incorporate other media, and/or break with established conventions.

The use of metatechniques that give co-players direct access to a character's mind is an important design decision. Participants are then expected 
to separate player's knowledge from character's knowledge: co-players will hear another character's voices-in-the-head, but as characters they will pretend they heard nothing. This creative approach gives more affordances for representing subjective perception. By contrast, if we insist on the unity of player/character knowledge, affordances are limited mainly to organiserdirected extradiegetic narratorial and symbolic markers communicated only to the 'target' player, and player-directed diegetic (behavioural) narratorial and content markers.

The character's perception of the storyworld is not represented in an external medium but dynamically developed as a player's mental construct, with constant filtering of 'what-I-perceive' from 'what-character-perceives'. In the case of quasi-perceptions and internal worlds, it creates different audience experiences for the target (perceiving) player and co-players. Unlike in films, comics, and video games, in which all audience members are exposed to the same representations of a character's subjectivity.

Embodied perception combined with unscripted multiplayer narrative agency puts the storyworld in the danger of unwanted metaleptic contact between one character's quasi-perceptions and another character's body. This results e.g. in limitations or additional efforts for GMs in the use of content and representational markers. This problem does not exist in recorded media, or even in interactive video games.

The affordances for the use of subjectivity markers are strongly linked to the degree of player/character unity assumed in the larp. If the larp strives for their perceptual unity, i.e. maximum overlap of player's and character's embodied perception of their surroundings, then it will not include somebody's quasi-perceptions which co-players must pretend not to see. Neither will it facilitate co-player's participation in another character's internal world, which the co-player would then have to filter out of his/her memory. Least of all would it take the risk of metaleptic collisions unless the nature of the storyworld allows it.

Nonetheless, the perceptual unity, or in fact any unity between players and their characters is a design choice. So are all principles I listed in the prototypical model of larp, with many individual games or whole subgenres following different paths. There is no universal agreement on whether freeforms and jeepforms are still larps, and whether larp should be counted among games, or interactive drama, or as a whole new genre in itself. The prototypicality of the presented model does not claim that larps should be like that or that most larps are like that. What I claim is that it is well- 
established in the history and current practice of the medium, and can serve as a stable frame of reference for comparison with other media.

As presented here, larp is multimodal in itself (speech, physical action, narration, game mechanics, costumes and stage decoration), and may contain an unlimited variety of media to enrich its experiential possibilities, becoming genuinely transmedial. Also, many larp productions have appeared as parts of larger transmedia universes. Hundreds of noncommercial larps for Game of Thrones, Star Wars, Lord of the Rings, Harry Potter, The Witcher etc. have been created by fan communities around the world. Moreover, in the recent years, larp has been noticed by the big entertainment companies and officially incorporated in their brands, examples ranging from official licensing or authorisation of independent larps (case of Witcher School, see Mochocki 2016) to larps and larp-like experiences developed by the copyright holder (case of Star Wars Hotel announced by Disney, see the press coverage) to larps whose outcomes will shape the storyworld for the whole franchise (case of Enlightenment in Blood for White Wolf's World of Darkness, discussed by Mochocki 2017). Recognizing the specific modes of representation in larp helps us to widen the scope of transmediality even more and may be a useful contribution to transmedia narratology, as the significance of larps in media franchising is clearly on the rise.

\section{BIBLIOGRAPHY}

Andreasen, Carsten. 2003. "The Diegetic Rooms of Larp". In As Larp Grows up: Theory and Methods in Larp, edited by Morten Gade, Line Thorup, and Mikkel Sander, 76-81. Frederiksberg: Projektgruppen KP03.

Ashby, Charlotte. 2017. "Playing Around the Event Expansive Pre-Game at College of Wizardry". In Once Upon a Nordic Larp ... Twenty Years of Playing Stories, edited by Martine Svanevik, Linn Carin Andreassen, Simon Brind, Elin Nilsen, and Grethe Sofie Bulterud Strand, 213-23. Helsinki: Ropecon.

Bienia, Rafael. 2016. Role-playing Materials. Braunschweig: Zauberfeder Verlag.

Booth, Paul. 2009. "Narractivity and the Narrative Database: Media-Based Wikis as Interactive Fan Fiction". Narrative Inquiry 19 (2): 372-92. doi:10.1075/ni. 19.2.09boo.

Bowman, Sarah Lynne. 2015. "Connecting Role-Playing, Stage Acting, and Improvisation”. Analog Game Studies. http://analoggamestudies.org/2015/05/con necting-role-playing-stage-acting-and-improvisation/. 
Bruun, Jesper. 2011. "Pre-Larp Workshops as Learning Situations". In Think Larp: Academic Writings from KP2011, edited by Thomas Duus Henriksen, 194215. Copenhagen: Rollespilsakademiet.

Chatman, Seymour Benjamin. 1990. Coming to Terms: The Rhetoric of Narrative in Fiction and Film. Ithaca, N.Y: Cornell University Press.

Edland, Tor Kjetil, Trine Lise Lindahl and Margarete Raaum. 2011. "Mad about the Boy”. In Do Larp: Documentary Writings from KP2011, edited by Lars Andresen, Charles Bo Nielsen, Luisa Carbonelli, Jesper Heebøll-Christensen, and Marie Oscilowski, 92-107. Copenhagen: Rollespilsakademiet.

Elam, Keir. 2005. The Semiotics of Theatre and Drama. Repr. New Accents. London: Routledge.

Fedoseev, Alexey. 2014. "Larps, Interactive Theatre and Participatory Arts". In The Cutting Edge of Nordic Larp: Knutpunkt 2014, edited by Jon Back, 103-11. Malmö: Knutpunkt.

Fludernik, Monika. 2005. Towards a Natural Narratology. London and New York: Routledge.

Fatland, Eirik. 2005. "Incentives as Tools of Larp Dramaturgy". In Dissecting Larp, edited by Petter Bøckman and Ragnhild Hutchison, 147-80. Oslo: Knutepunkt.

Hitchens, Michael and Anders Drachen. 2009. "The Personal Experience of Narratives in Role-Playing Games”. In 2009 AAAI Symposium on Intelligent Narrative Technologies II, 53-61. Stanford: AAAI Press.

Hakim Bey and Freddie Baer. 1994. Immediatism: Essays by Hakim Bey. Edinburgh, Scotland: AK Press.

Harviainen, J. Tuomas. 2007. "Live-Action, Role-Playing Environments as Information Systems: An Introduction". Information Research, December. http://www.informationr.net/ir/12-4/colis/colis24.html.

Heebøll-Christensen, Jesper, Kristoffer Thurøe and Peter Munthe-Kaas. 2011. "Delirium". In Do Larp: Documentary Writings from KP2011, edited by Lars Andresen, Charles Bo Nielsen, Luisa Carbonelli, Jesper Heebøll-Christensen, and Marie Oscilowski, 72-91. Copenhagen: Rollespilsakademiet.

Jost, Francois. 2004. "The Look: From Film to Novel: An Essay in Comparative Narratology". In A Companion to Literature and Film, edited by Robert Stam and Alessandra Raengo, 71- 80. Malden, MA: Blackwell Pub.

Lampo, Marjukka. 2011. "Larp, Theatre and Performance". In Think Larp: Academic Writings from KP2011, edited by Thomas Duus Henriksen, 88-103. Copenhagen: Rollespilsakademiet.

Loponen, Mika and Markus Montola. 2004. "A Semiotic View on Diegesis Construction". In Beyond Role and Play: Tools, Toys and Theory for Harnessing 
the Imagination, edited by Markus Montola and Jaakko Stenros, 39-51. Helsinki: Ropecon ry.

Mäyrä, Frans. 2008. An Introduction to Game Studies: Games in Culture. London: SAGE.

McIntyre, Dan. 2006. Point of View in Plays: A Cognitive Stylistic Approach to Viewpoint in Drama and Other Text-Types. Amsterdam; Philadelphia: J. Benjamins.

Mochocki, Michał. 2016. "From College of Wizardry to Witcher School: A Comparative Study of Franchise Larp Design”. Homo Ludens, no. 9: 197-223.

Mochocki, Michał. 2017. "Digital + Non-Digital + Intimately Physical. World of Darkness Berlin as Transmedia Franchise Entertainment”. Presented at Central and Eastern European Game Studies Conference, Trnava, Slovakia, 28th September.

Mochocki, Michał. "From Live Action to Live Perception. Player Character's Point of View", forthcoming.

Montola, Markus. 2003. "Role-Playing as Interactive Construction of Subjective Diegeses". In As Larp Grows up: Theory and Methods in Larp, edited by Morten Gade, Line Thorup, and Mikkel Sander, 82-89. Frederiksberg: Projektgruppen KP03.

Montola, Markus. 2010. "The Positive Negative Experience in Extreme Role-Playing”. In DiGRA Nordic'10: Experiencing Games: Games, Play, and Players, 1-8. http:/www.digra.org/digital-library/publications/the-positive-negativeexperience-in-extreme-role-playing/.

Montola, Markus. 2012. "First Person Audience and the Art of Painful Role-Playing”. In Immersive Gameplay: Essays on Participatory Media and Role-Playing, edited by Evan Torner and William J. White, 13-30. Jefferson, N.C: McFarland \& Co.

O'Neill, Shaleph. 2008. Interactive Media: The Semiotics of Embodied Interaction. London: Springer.

Pearce, Celia. 2016. "Role-Play, Improvisation, and Emergent Authorship". In The Oxford Handbook of Critical Improvisation Studies, edited by George E. Lewis and Benjamin Piekut, 2:445-68. Oxford University Press.

Ryan, Marie-Laure. 1991. Possible Worlds, Artificial Intelligence, and Narrative Theory. Bloomington: Indiana University Press.

Ryan, Marie-Laure. 2001. Narrative as Virtual Reality: Immersion and Interactivity in Literature and Electronic Media. Parallax. Baltimore: Johns Hopkins University Press.

Ryan, Marie-Laure. 2014. "Story/Worlds/Media: Tuning the Instruments of a Media- Conscious Narratology”. In Storyworlds across Media: Toward a Me- 
dia-Conscious Narratology, edited by Marie-Laure Ryan and Jan-Noël Thon, 25-49. Lincoln; London: University of Nebraska Press.

Ryan, Marie-Laure. 2015. Narrative as Virtual Reality 2: Revisiting Immersion and Interactivity in Literature and Electronic Media. Second edition. Baltimore: Johns Hopkins University Press.

Ryan, Marie-Laure and Jan-Noël Thon. 2014. "Storyworlds across Media: Introduction”. In Storyworlds across Media: Toward a Media-Conscious Narratology, edited by Marie-Laure Ryan and Jan-Noël Thon, 1-21. Lincoln; London: University of Nebraska Press.

Sandberg, Christopher. 2004. "Genesi. Larp Art, Basic Theories". In Beyond Role and Play: Tools, Toys and Theory for Harnessing the Imagination, edited by Markus Montola and Jaakko Stenros, 264-288. Helsinki: Ropecon.

Shirky, Clay. 2008. Here Comes Everybody: The Power of Organizing without Organizations. London: Penguin Books.

Stenros, Jaakko and Markus Montola. 2010. "The Paradox of Nordic Larp Culture". In Nordic Larp, edited by Jaakko Stenros and Markus Montola, 1st print, 15-29. Stockholm: Fea Livia.

Talmy, Leonard. 2000. Toward a Cognitive Semantics. Language, Speech, and Communication. Cambridge, Mass: MIT Press.

Taiwo, Olu. 2009. "The Physical Journal: The Living Body That Writes and Rewrites Itself". In Sensualities/Textualities and Technologies: Writings of the Body in 21st Century Performance, edited by Susan Broadhurst and Josephine Machon, 103-16. Basingstoke; New York: Palgrave Macmillan. http://public.eblib.com/choice/publicfullrecord.aspx?p=598049.

Thon, Jan-Noël. 2014. "Subjectivity across Media: On Transmedial Strategies of Subjective Representation in Contemporary Feature Films, Graphic Novels, and Computer Games". In Storyworlds across Media: Toward a MediaConscious Narratology, edited by Marie-Laure Ryan and Jan-Noël Thon, 67102. Lincoln; London: University of Nebraska Press.

Thon, Jan-Noël. 2016. Transmedial Narratology and Contemporary Media Culture. Lincoln: University of Nebraska Press.

Torner, Evan. 2017. "Tensions Between Transmedia Fandom and Live-Action RolePlay". In Once Upon a Nordic Larp ... Twenty Years of Playing Stories, edited by Martine Svanevik, Linn Carin Andreassen, Simon Brind, Elin Nilsen and Grethe Sofie Bulterud Strand, 297-303. Oslo: Knutepunkt.

Ungerer, Friedrich and Hans-Jörg Schmid. 2006. An Introduction to Cognitive Linguistics. 2nd ed. New York: Longman.

Wrigstad, Tobias, Tobias. 2008. "The Nuts and Bolts of Jeepform". In Playground Worlds. Creating and Evaluating Experiences of Role-Playing Games, edited 
by Markus Montola and Jaakko Stenros, 125-38. Helsinki: Solmukohta: Ropecon. http://www.solmukohta.org/pub/Playground_Worlds_2008.pdf.

Zagal, Jose and Sebastian Deterding, eds. in press. Role-Playing Game Studies: Transmedia Foundations. Abindgon: Routledge. 